\title{
Innovative Ideas of Enterprises and Institutions' Human Resources Management to Personnel Archives Management
}

\author{
PU Zongshan ${ }^{1,2}$ and Hang Yiran ${ }^{1}$ \\ ${ }^{1}$ Sichuan Technology an Business University, Chengdu 611745, Sichuan, China; \\ ${ }^{2}$ Sichuan DRY Enterprise Management Consulting CO., LTD, Chengdu 610072, Sichuan, China
}

Keywords: Human Resources Management; Personnel Archives Management

\begin{abstract}
This century is an era of knowledge-based economy, in which the core of management rests in knowledge management; all competitions are attributed to talent competition. For these reasons, human resource management has developed to be the core of the knowledge-based management. The advantages and disadvantages of personnel archives management play an extreme impact on the effectiveness of human resources management. Then, the personnel archives wok becomes an important pillar of enterprises and institutions' human resources management. Personnel archives management and human resources management are an organic whole, which cannot be separated, and have to develop simultaneously. In enterprises and institutions, a good management of personnel archives will enormously empower human resource management, thus improving the core competitiveness. In the age of knowledge-based economy, the traditional personnel archives management has lagged behind the trend of the times; the modern human resource management of enterprises and institutions has raised new requirements for personnel archives management. It is imperative to reform the personnel archive management.
\end{abstract}

\section{Introduction}

Knowledge becomes the first element driving the human development, but also the most precious human resource. In the age of knowledge-based economy, the core of management rests in knowledge management; all competitions are attributed to talent competition. The advantages and disadvantages of personnel archives management exert an extreme impact on the effectiveness of human resources management. Then, the personnel archives work becomes an important pillar of enterprises and institutions' human resources management.

The main functions of enterprises and institutions' personnel archives as important part of their archives can be concluded generally from the following points:

(1) An important method examining and knowing well employees

(2) A dispensable basis for human resource management

(3) An information and data basis for human resource development

(4) An important pillar of enterprises and institutions' knowledge management

(5) Important representations of enterprises and institutions' culture

Personnel archives management is a management job; from its major role in enterprises and institutions, personnel archives management and human resources management are an organic whole, and the relationship between the two sides is like that between fish and water which are inseparable and simultaneously develop. Human resources management is dependent on the information available in the personnel archives; all the business activities related to personnel archives management are to input or output personnel archives information and serve human resources management activities. In enterprises and institutions, a good management of personnel archives will enormously empower the human resources management, thus improving the core competitiveness.

In the age of knowledge-based economy, the traditional personnel archives management has lagged behind the trend of the times; the modern human resources management of enterprises and institutions has raised new requirements for personnel archives management. It is imperative to reform personnel archives management. 
Human resources refer to the labor capacities of human, formed based on congenital factors and with the aid of human capital investment and distinctive life and social practice, including mental and physical aspects. In contrast to material resources, human resources feature initiative, duality, creativity, renewability, timeliness, and sociality because of its dependence on the biological and social humans. According to the characteristics of human resources, human resources management is a modern management idea centered at "humans" and seeing humans as the most important resources; it is also a management model majored at humans, aiming to let humans well suited with their place and give a full play to their ability, dynamically combine organizational goal with personal goal, and match the organizational growth with the personal ability. The basic purpose of human resource management is to build a great, high quality, and highly-united team and a self-motivated and self-restricted mechanism of promoting excellent talents to stand out, and foster a good organizational atmosphere and corporate culture. What human resource management reflects is the advanced management idea of "the future of enterprises and institutions is decided by talents".

Personnel archives are produced in the personnel management activities of national institutions and social organizations, which are texts, tables, and other various forms of historical records saved based on a personal name to record and mirror personal experience, moral performance, and job performance. Personnel archives are mainly originated from the personnel management activities of some units, which are the original records to reflect personal experience, ideological and moral performance, business performance, individual characteristics, specialties and hobbies, the completely-handled document materials of application and preservation values, special rolls/volumes characterized by personal name, the historical, comprehensive and important basis with real, dynamic, and confidential characteristics to comprehensively know and correctly select employees, and important part of national archives.

\section{Innovative Ideas of the New Trend of Modern Human Resources Management to Personnel Archives Management}

The times are always on the development. There are new trends to emerge in human resources management after nearly half a century of development, raising more and newer requirements for the personnel archives work. Therefore, only with a good understanding of these trends, the reform of the personnel archives work will be fully implemented.

These innovative ideas can be summarized as the following.

First, a core value system is established in enterprises and institutions. In the modern human resources management, the business management of enterprises and institutions is regarded as a moral behavior; corporate culture changes into an important supporting power of the survival and development of enterprises and institutions.

Second, a multi-level value evaluation system is established to transform the traditional personnel appraisal system into a value evaluation system of human resources management, a single evaluation system into a multi-level, comprehensive evaluation system, individual-elements-based appraisal into the evaluation of excellent performance factors, and individual-performance based appraisal into the evaluation of enterprises and institutions' performance, organizational performance and team performance.

Third, a compensation rewarding system oriented at performance is constructed. When the compensation rewarding functions are stressed, the compensation incentive functions are more greatly valued; organizational and individual performances are used as the basis of compensation on the ground of using behaviors and skills; team performance rewards and incentives - team compensation are underlined, and long-term incentives of employee shareholding and stock option are strengthened in the compensation system.

Fourth, professionalization is used as an important symbol for measuring the level of human resources management. Professional elements are composed of the knowledge structure and skills, professional quality, professional ethics, professional spirit, professional rules, professional values, and professional language within the world economic integration. 
Many new trends in the development of modern human resources management have raised more and newer requirements for personnel archives management.

First, personnel archives work, as important part of enterprise archives work, is supposed to reflect enterprises and institutions' culture and serve the core value system of enterprises and institutions.

Second, personnel archives work is the foundation of enterprise value evaluation system; value evaluation information is the important source of personnel archives information. The personnel information from the personnel archives should be transferred from the originally simple evaluation information into multi-level, comprehensive evaluation information. Meanwhile, the organizational and team information are stressed while paying attention to personal information, in order to maintain the connection and consistency between personal information and organizations.

Third, personnel archives work is an important basis of the value distribution system of enterprises and institutions: the records and update of value distribution result and feedback information are necessarily notices.

Fourth, professionalization is an important symbol for measuring the level of human resources management. As a result, in the personnel archives work, attention is necessarily paid to the collection of professional information and the timely utilization.

\section{Perspective for the Problems of Enterprises and Institutions' personnel Archives Management}

At present, there are many problems in the personnel archives management of enterprises and institutions, which have directly restricted the development of enterprises and institutions' personnel archives work, caused extremely great troubles to the personnel archives management of enterprises and institutions, and affected the development of enterprises and institutions.

Weak Awareness of Service and a Lack of Pioneering Spirit. The ideas of enterprises and institutions' personnel archives management and many personnel archives management departments are worm-eaten; many management personnel lack a pioneering spirit and do not fundamentally realize the archives work is service-oriented. The effectiveness of the supplies and utilization of the archives information largely depends on the advantages and disadvantages of the archives service work.

However, the personnel archives management in today's enterprises and institutions still play a role of keeper, which only passively receive archives, and even regard themselves as the "god" to hold a bad attitude toward the persons who want to use archives. In a long term, archives users will become less and less; some departments even do not submit their archives to archives department for maintenance; the significance of archives department will be increasingly under suspicion, finally putting the position of archives department into jeopardy.

Weak Awareness of Cooperation and a Lack of Cooperation with Related Departments. Enterprises and institutions' personnel archives management is closely related to many other tasks, but not a sole entity. However, in many enterprises and institutions, personnel archives management is divorced from human resources management. Personnel archives seldom provide the information of the employees required by human resources department. Accordingly, human resources department will not submit the information of new employees to archives department.

Weak Awareness of Competition and a Lack of Timeliness Concept. The effect of the traditional ideas on archives department is extremely great; archives department is not aware of competition, and do not build up a concept of timeliness, so that the work efficiency of the archives department is universally not high. But in the age of the knowledge-based economy, these have exerted a lethal effect on enterprises and institutions.

Imperfect Personnel Archives Management System and a Lack of Scientific and Advanced Ideas. With regard to the system, the relatively lagging-behind collection, identification, classification, archiving, consultation, and updates of personnel archives make the necessary information failed to be archived and bound, and the flowing archives not to be timely removed. As a result, archives are in chaos; the archives necessary to be queried are unavailable; a person's history fails to be really, completely reflected. 
Unscientific ideas of the traditional personnel archives classification and the one-sidedness of archives contents. Traditional personnel archives are mainly divided into three types: cadres, students, and workers. Along with the development of the times, this way of classification fails to satisfy the needs of the modern personnel archives management. In the modern enterprises and institutions, the diversification of specialty and working contents decides the diversity of the posts and labor divisions of employees; the emergence and increase of mobile personnel in enterprises and institutions have brought about new challenges to personnel archives management.

The contents of the previous personnel archives are not enough complete and also one-sided. This is mainly manifested in "four stresses and four neglects" of personnel archives management: stressing the political and historical issues, but neglecting work performance; stressing family relations, but neglecting real performance; stressing ideology and moral character, but neglecting ability and achievements; stressing mistakes, but neglecting achievements. In addition, there are more formulized materials in personnel archives. The incoherence and incomprehensiveness of personnel archives give rise to the poor utility in reality, so that it does not play a role of serving human resource management in enterprises and institutions.

Restriction of Personnel Archives Management Personnel's Comprehensive Quality on the Development of Personnel Archives Management. The structure of the personnel working in archives management department is not reasonable; the current archives personnel often have many problems such as a lack of pioneering spirit and competitive consciousness, narrow scope of knowledge, and unreasonable structure of knowledge, thus deeply restricting the process and development of the personnel archives management.

Restriction of Backward Personnel Archives Management Methods on the Development of Personnel Archives Functions. Now, the personnel archives management in many enterprises and institutions are in the phase of experience management and manual management. Under the condition of the increasingly enhanced role of personnel archives, this way fails to cater to the needs of the actual work.

\section{Strengthening and Improving Personnel Archives Management to Make it Accommodate the Innovation of Modern Enterprises and Institutions' Human Resources Management}

The reform of personnel archives management, which is necessarily based on the due duties and responsibilities and current situation, needs to actively expand the functions of management in the era of knowledge-based economy, promoting personnel archives work to really adapt to the innovation of enterprises and institutions' human resources management, and making new contributions to the development of enterprises and institutions.

Enhancing Service Awareness to Urge Archives Management to Actively Serve Archives Users. In the era of knowledge economy, personnel archives management is in need of updating ideas, correcting their attitudes, changing the long-term passive service model, enhancing service awareness, and forwardly providing information service for the human resources management of enterprises and institutions. Personnel archives management serves human resources management, and drives the human resources management of enterprises and institutions, and therefore, it is not only one of important means of human resources management to know, choose, use, retain, and foster personnel, but also the foundation of the knowledge management of enterprises and institutions. To this end, personnel archives management needs to be very clear about the situation, hold a right attitude, and enhance service awareness.

Strengthening Cooperative Awareness and the Coordination With Relevant Departments. In the background of knowledge economy, all departments in enterprises and institutions are interrelated and interdependent, but not independent. Archives department, which manages the practice activity carriers and knowledge crystallization of enterprises and institutions, is especially closely linked to all other departments. All business activities of personnel archives management aim to input or output personnel archives information and serve the human resources management activities. The main sources of the personnel archives information are the human resources 
management activities of enterprises and institutions. Furthermore, personnel archives management needs to timely report relevant information to human resources management department. It is an important way to strengthen the communication and cooperation with human resources departments, in order to do a good job in personnel archives management.

Establishing a Sense of Competition and Enhancing Timeliness Awareness. In the era of knowledge economy, knowledge is the most valuable resource, while time is an important factor of winning the competition. The efficiency of the personnel archives management is also a reflection to the whole efficiency of enterprises and institutions. Personnel archives management needs not merely timely, accurately provide archival information, but also shortens the periods of information feedback, collection, and recycle. Then, the close cooperation of personnel archives department with other departments becomes a must. Within personnel archives management department, it is necessary to encourage the internal competition, improve the post responsibility system, introduce the concept of human resources management, and strengthen target management and quota management.

Establishing a Sound, Scientific and Reasonable Personnel Archives Management System. In personnel archives management, the rules and regulations that do not adapt to the new situation, circumstances, and tasks are necessarily changed; a new, more scientific and rational system of personnel archives management is necessarily established for the goal of pushing personnel archives work more systemic and legal. The collection of archives is supposed to be timely and complete; the identification of archives has to follow the archives classification law of "use with evidences and discard with reasons", making sure the work rigorous and scientific; the borrowing and reading of archives are necessarily analyzed based on the specific conditions, and the human resources management department is necessarily distinctive with other departments to stress the security of archives; the update of archives is also necessarily timely, accurate and complete, paying especial attention to the timely and active replenishment and collection of the "present" archives.

Establishing a Scientific Personnel Archives Classification System and Enriching the Contents of Archives. Personnel archives are necessarily classified according to the internal situation of enterprises and institutions; a scientific, reasonable personnel archives classification system suiting the actual conditions of enterprises and institutions is established, but not rigidly adhered to the traditional classification.

In the era of knowledge economy, the news ideas of human resources management must enrich the contents of personnel archives, letting them reflect person's ability comprehensively from multiple directions. The contents of personnel archives must stress the dynamic and static combination, horizontal and vertical combination, and qualitative and quantitative combination. Dynamic and static combination refers to stressing the timely supplement to dynamic information. Vertically, personnel archives reflect a person's history, but also his reality; horizontally, personnel archives are supposed to reflect a person's ideological level, political attitude, knowledge, working ability, aspiration and character and so on. In modern times, it is necessary for personnel archives to especially emphasize the contents such as recent assessment, recruitment, work transfer, labor contract, rewards and punishments, compensation levels, educational levels, professional titles, professional natures, actual work performance, creation, and invention. Quantitative and qualitative combination means the contents of personnel archives include not only qualitative conclusion, but also quantitative description, in order to improve the availability of personnel archives information.

Introducing High-quality Talents, Strengthening Personnel Training, and Improving Personnel Quality. Talents are the motive forces of enterprises and institutions to make progresses and developments, and this is also similar to archives management department. In the era of knowledge economy, the modernization is continuously improved, and then the introduction of high-quality talents is an inevitable requirement of the development of personnel archives work. When high-quality talents are introduced, enterprises and institutions must also pay attention to the training of archives personnel, promoting them to meet the new requirements under the new situation. As a result, the quality of personnel archives management will be comprehensively improved.

Speeding up the Scientific and Modernized Process of Personnel Archives Management. Scientific and modernized personnel archives management includes scientific and modernized 
management means, but also scientific and modernized management ideas. Scientific and modernized management ideas refer to the above mentioned awareness, not to be discussed then. Scientific and modernized management means aim to ultimately establish an employee information system based on the personnel archives information of enterprises and institutions. The preliminary requirement of the system is to establish a man-machine integrated technical management system and realize the computer-based management of personnel archives.

\section{Conclusion}

The times and humans always develop without a stop. The current information-based century is the age of knowledge. Information, materials, and energy have become the three major resources of human society; knowledge changes into the first element to drive human development; talents turn into the key of competition. Archives are the cohesions of all creations and knowledge of enterprises and institutions, and bear the information of enterprises and institutions. Thus, archives management is no longer of little importance. However, today's archive management level cannot fully adapt to the requirements of enterprises and institutions for development. Personnel archives are only part of the archives of enterprises and institutions. When the reform of personnel archives work is strengthened, it is necessary to positively promote the overall reform of the personnel archives management work in enterprises and institutions. Meanwhile, it is necessary to set up a sound archives management system, improve the quality of personnel archives, speed up the modernized progress of the management work, and change the previously negative pattern of archives management by starting with enhancing the awareness, so as to facilitate the archives management work to really adapt to the requirements of the knowledge-based economy, make more and greater contributions to the development of enterprise and institutions, and initiate a new situation of archives management work.

\section{References}

[1] CHEN Zhiwei. The Fifth-generation Management [M]. China's Prices Press, 2011.6.

[2] ZHOU Aiyun. Views on the Competitive Weapons of the Modern Enterprises and Institutions - human resources management [M]. Publishing house of China University of Mining, 2015.5.

[3] LI Yanhua. Archives Management [M]. Chinese People's University Press, 2011.1.

[4] SONG Peijie. Human Resource Management [J]. Journal of Zunyi Medical College, 2009.1.

[5] Xiaohua. Discussion on the Personnel Archives Management in Enterprises and Institutions [J]. Journal of Nantong Vocational University, 2005: 75-77.

[6] Sun Shuoshi. A Combination of Specification with Provision and Utilization-Discussion on the Personnel Archives Management of Mobile Personnel [J]. Journal of Chinese Archives, 2007.5: 25-26.

[7] TANG Chenglian. Discussion on the Characteristics, Basic Principles, and Development Trend of China’s Modern Enterprises and Institutions [J]. Journal of Secretarial Grind Gui Second Academic Year: 10-12.

[8] ZHU Limei. Development and Utilization of the Archives Information in Enterprises and Institutions [J]. Communication of Archives Science, 2015.5: 36-38.

[9] SUN Hongbing. Exploration on the Science of Personnel Archives Management [J]. Journal of Beijing Second Foreign Languages Institute, 2005.4:114-118.

[10] ZHU Yuyuan. Study on the Modern Personnel Archives Management System in China [J]. Books Intelligence Knowledge, 1999.2:26-28. 
[11] CHEN Ping. Several Reflection on the Personnel Archives Management Work in Small and Medium-sized Enterprises and Institutions [J]. Archives and Construction, 2009.11: 50-55. 